\title{
A internacionalização do Banco do Brasil em dois momentos distintos de sua história
}

Armando Dalla Costa*

Elson Rodrigo de Souza-Santos*

\begin{abstract}
RESUMO - O Banco do Brasil (BB) é um dos líderes do mercado bancário nacional e também do processo de internacionalização das grandes instituições financeiras brasileiras formadas por Itaú/Unibanco e, em menor medida, Bradesco. A estratégia de internacionalização não é nova para o BB, tendo antecedentes da busca de uma expansão agressiva nas décadas de 1960/1970, mas que foram eclipsadas pela crise macroeconômica brasileira e da instituição, voltando à tona na década de 2000. Recentemente, a característica marcante do banco é integrar a expansão internacional, aliada à necessidade de manter-se competitivo frente aos concorrentes privados e corroborar a estratégia estatal para criar empresas internacionalizadas. O objetivo do texto é apresentar a trajetória de crescimento da instituição no mercado interno e explicitar o processo de internacionalização do BB, além de apontar os desafios que a instituição enfrenta atualmente no cenário externo.
\end{abstract}

Palavras-chave: Banco do Brasil. Cenário Externo. Internacionalização.

\section{INTRODUÇÃO}

O Banco do Brasil (BB) pode ser considerado o mais antigo do país, iniciando suas atividades em 1808 via alvará do príncipe regente D. João, mas sofreu profundas transformações ao decorrer do tempo. Exerceu funções de autoridade monetária, agente financeiro do Governo Federal, instrumento de direcionamento de crédito para agricultura, exportações, indústria e, por fim, papel de banco múltiplo. Atualmente é um dos maiores agentes financeiros brasileiros e utiliza as funções públicas como vantagens competitivas.

No âmbito externo, o BB internacionalizou-se com uma estratégia agressiva de inserção nas décadas de 1960-1970, eclipsada nos anos seguintes devido à crise econômica brasileira e a situação delicada das finanças da instituição. No governo Lula (2003-2010), sua estratégia de inserção passou a enfatizar a necessidade de conquistar novos mercados e fortalecer-se frente os competidores privados, tanto no âmbito interno como no internacional.

Para analisar a estratégia de internacionalização do Banco do Brasil, o trabalho está

\footnotetext{
* Doutor em História Econômica pela Universidade de Paris III. É professor do Departamento de Economia e do Programa de Pós-Graduação em Desenvolvimento Econômico da Universidade Federal do Paraná. Endereço eletrônico: ajdcosta@ufpr.br.

** Mestre em Economia pelo Programa de Pós-Graduação em Desenvolvimento Econômico da Universidade Federal do Paraná. É membro do Núcleo de Pesquisa em Economia Empresarial. Endereço eletrônico: elson129@ gmail.com.
} 
organizado em três partes. A primeira apresenta a história do BB, a segunda fala sobre o quadro atual do BB. A terceira trata da estratégia de internacionalização, seguida das principais conclusões.

\section{PERSPECTIVA HISTÓRICA DO BANCO DO BRASIL}

Apesar do Banco do Brasil se orgulhar de ter mais de 200 anos e figurar entre as instituições financeiras mais antigas do país, a história patrocinada pelo BB (2010) enfatiza que existiram vários "Bancos do Brasil”" e períodos de descontinuidade (1833-1853 e 1893-1905). O primeiro BB foi fundado em 1808 e liquidado em 1833. O segundo renasceu em 1853 através da fusão do banco do Barão de Mauá com o Banco Comercial do Rio de Janeiro, desaparecendo em decorrência da fusão com o Banco da República dos Estados Unidos do Brasil, que levou ao surgimento do Banco da República do Brasil. Em 1905 o BB foi refundado, tomando forma semelhante à atual, como uma das instituições-chave para o apoio ao desenvolvimento nacional. No século XX, as funções de instrumento de implementação da política monetária foram paulatinamente sendo retiradas e ganhando cada vez mais características de um banco múltiplo.

$\mathrm{Na}$ história das instituições financeiras nacionais aconteceram diversas mudanças e transformações. Uma delas foi a reforma de 1964, que trouxe a iniciativa privada para o financiamento de longo prazo (STUDART, 1995, p. 117-118). Para o BB, tal mudança significou a perda de atribuições de autoridade monetária para o recém-fundado Banco Central do Brasil $(\mathrm{BACEN})^{1}$. Entretanto, o Banco do Brasil permaneceu como "autoridade monetária híbrida" até 1986 ao preservar a estrutura operacional e administrativa de agente financeiro do Tesouro Nacional como arrecadador e pagador, caixa disponível para o Tesouro e das entidades federais, principal instrumento executor da política financeira, encarregado dos programas oficiais de crédito, da política de estoques governamentais (compra e venda de produtos agropecuários), entre outros.

O projeto do BB de se transformar em um banco múltiplo ganhou força na segunda metade da década de 1980. Em 1987 nasceram quatro subsidiárias: BB Financeira S. A.; BB Leasing S. A.; BB Corretora de Seguros e Administradora de Bens S. A. e BB Administradora de Cartões de Crédito S. A.. No ano seguinte, passou a oferecer novos produtos como o Ourocard, primeiro cartão de múltiplo uso do mercado e serviços como leasing financeiro, além da criação de uma nova subsidiária, a BB Banco de Investimento S. A. (BB, 2011). A reforma

1 O Banco Central do Brasil (BACEN), autarquia federal, integrante do Sistema Financeiro Nacional, foi criado em 31 de dezembro de 1964, com a promulgação da Lei n. 4.595. Antes da criação do Banco Central, o papel de autoridade monetária era desempenhado pela Superintendência da Moeda e do Crédito (SUMOC), pelo Banco do Brasil (BB) e pelo Tesouro Nacional. 
bancária de 1988 retirou a conta movimento do BB, levando o banco a deixar de exercer as funções de caixa do Tesouro Nacional (BB, 2010, p. 60-61).

Na década de 1990 a linha seguida foi de sanear o banco e aprofundar a capacidade de competição e atuação no mercado frente às instituições privadas, adotando critérios mais rígidos de gestão de riscos, gestão transparente, novos produtos e serviços, ampliação na atuação dos mercados de capitais, varejo e seguridade. Esta nova atitude ajudou a instituição a receber, em 1998, o certificado ISO 9002 em análise de crédito, o rating nacional máximo da Atlantic Rating "AAA", classificado como instituição da melhor qualidade e considerado pela Bolsa de Valores do Rio de Janeiro a melhor companhia aberta de 1998 (BB, 2011). A mudança de rumos no BB é criticada por autores como Araújo (2001, p. 78-79), por descaracterizar a função de banco público e minimizar as funções de bancos estatais.

\section{QUADRO ATUAL E ESTRATÉGIA DE ATUAÇÃO}

O Tesouro Nacional é o acionista majoritário do BB. Entretanto, pouco menos da metade das ações estão pulverizadas entre diversos agentes privados e fundos de pensão, com destaque para a participação de 12\% de capital estrangeiro (Gráfico 1).

\section{GRÁFICO 1- ACIONISTAS DO BANCO DO BRASIL: 2009 (EM \%)}



FONTE: BB (2010).

NOTA: * Ações pulverizadas no mercado.

Quando o BB tem seus números comparados com os grandes bancos nacionais, Itaú/ Unibanco e Bradesco, configura-se como o maior banco múltiplo brasileiro, e sua estratégia de expansão da década de 2000 buscou defender a liderança. Mesmo a fusão entre Itaú e Unibanco 
não foi capaz de desbancar o Banco do Brasil, apesar de chegar próximo e superar em alguns indicadores (Tabela 1).

TABELA 1 - COMPARATIVO ITAÚ/UNIBANCO, BRADESCO E BANCO DO BRASIL: 2008-2009

\begin{tabular}{|c|c|c|c|}
\hline & Itaú Unibanco & Bradesco & Banco do Brasil \\
\hline Lucro líquido (em bi de $\mathrm{R} \$$ ) & 10,1 & 8,01 & 8,8 \\
\hline Patrimônio líquido (em bi de $\mathrm{R} \$$ ) & 50,7 & 41,75 & 36,12 \\
\hline Depósitos (em bi de R $\$$ ) & 190,8 & 171,07 & 337,56 \\
\hline Operações de crédito (em bi de $\mathrm{R} \$$ ) & 278,4 & 190,99 & 224,8 \\
\hline Ativos totais (em bi de $\mathrm{R} \$$ ) & 608,3 & 506,22 & 708,55 \\
\hline Correntistas (em milhões) & 23,4 & 20,9 & 32,36 \\
\hline Eficiência operacional (menor, mais eficiente) & 42,4 & 41 & 41,9 \\
\hline $\mathrm{N}^{0}$ de agências & 3.948 & 3.454 & 4.897 \\
\hline $\mathrm{N}^{\mathrm{o}}$ de caixas eletrônicos & 30.276 & 30.657 & 45.442 \\
\hline $\mathrm{N}^{\circ}$ de empregados & 106.210 & 85.072 & 113.888 \\
\hline
\end{tabular}

FONTE: Banco do Brasil (2010b); Bradesco (2010) e Itaú Unibanco (2010b).

Ao olhar as transformações do BB, emerge a estratégia de solidificação como conglomerado financeiro de capital aberto que busca eficiência e lucratividade. Assim, o BB perde as características de banco público, que sacrifica o desempenho em nome de seu papel como braço do Estado. Em contraponto, ganha importância a visão de mercado, sendo necessário a expansão e o fortalecimento para ser competitivo e enfrentar as instituições privadas nacionais e estrangeiras.

\section{PROCESSO DE INTERNACIONALIZAÇÃO DO BANCO DO BRASIL}

$\mathrm{Na}$ história "moderna" do BB, abrangendo o período pós-1945, a internacionalização aparece como inserida na sua estratégia de atuação. A primeira onda ocorreu nas décadas de 1960/1970, acompanhando a integração financeira e operações internacionais dos grandes bancos. A segunda na década de 2000, em que não basta ter operações no exterior, mas também conquistar mercados de varejo locais, exigindo maior envolvimento (Tabela 2).

TABELA 2 - EXPANSÃO INTERNACIONAL DO BANCO DO BRASIL: 1960-1980

\begin{tabular}{|c|c|}
\hline Ano & Fato \\
\hline 1967 & $\begin{array}{l}\text { - Agências na Bolívia em Santa Cruz de la Sierra. } \\
\text { - Negociações para instalação de agências no Peru. } \\
\text { - Filiais e escritórios na Cidade do México (México), Bogotá (Colômbia), Caracas (Venezuela) e Quito } \\
\text { (Equador). }\end{array}$ \\
\hline 1969 & $\begin{array}{l}\text { - Autorização para abertura de filial em Nova York tendo como justificativa o intercâmbio comercial e } \\
\text { financeiro entre Brasil e Estados Unidos. }\end{array}$ \\
\hline 1970 & $\begin{array}{l}\text { - Inauguração da agência em Hamburgo (Alemanha) e início do funcionamento de escritórios em Paris } \\
\text { (França), Londres (Grã-Bretanha) e Tóquio (Japão). } \\
\text { - Instalação em Londres, maior mercado financeiro mundial, onde passou a participar do mercado de } \\
\text { euromoedas e "reciclagem de petrodólares". }\end{array}$ \\
\hline 1971 & $\begin{array}{l}\text { - O Banco contava com } 975 \text { agências em território nacional e } 14 \text { no exterior. } \\
\text { - Criação da European Brazilian Bank Ltd. (Eurobraz), uma empresa de investimentos. Posteriormente, } \\
\text { associados a Cia. Arabe et Internationale D’Investissement de Luxemburgo, o Banque Arabe et } \\
\text { Internationale D' Investissement em Paris, e o Brazilian American Merchant Bank de capital exclusivo } \\
\text { do BB em Grand Cayman. }\end{array}$ \\
\hline
\end{tabular}


TABELA 2 (CONTINUAÇÃO) - EXPANSÃO INTERNACIONAL DO BANCO DO BRASIL: 1960-1980

\begin{tabular}{c|l}
\hline Ano & \multicolumn{1}{c}{ Fato } \\
\hline 1977 & $\begin{array}{l}\text { - Escritórios de representação em Sydney (Austrália) e Lagos (Nigéria). Além da participação em em- } \\
\text { preendimentos diversos e representado por 36 agências. }\end{array}$ \\
\hline 1980 & $\begin{array}{l}\text { - Rede externa com 61 unidades, três subsidiárias, presente em Viena (Austria), Macau e estudos para a } \\
\text { instalação de dependências em Varsóvia (Polônia). }\end{array}$ \\
\hline & $\begin{array}{l}\text { - Criação da BB-Leasing Company Ltd., sediada em Grand Cayman, visando o financiamento do } \\
\text { arrendamento das plataformas de prospecção de petróleo para a Petrobras. Na Africa Mediterrânea, } \\
\text { abriu dependências no Cairo, Casablanca e Túnis; ao sul do Saara em Dakar e Libreville. Em Paris, } \\
\text { inaugurou a BB-Tours Voyages et Tourisme visando a ampliação do turismo para o Brasil. }\end{array}$ \\
\hline
\end{tabular}

FONTE: BB (2010).

NOTA: Tabela construída pelos autores.

O primeiro impulso para a internacionalização foi quebrado em 1977 com a reorientação das ações do BB para o mercado interno. Porém, o BB (BB, 2010) estava tão envolvido com o mercado externo que não havia como retroceder totalmente. Diante da nova situação, decidiu-se enxugar a estrutura da instituição em função do início da crise macroeconômica brasileira e pela crise interna do Banco.

Na década de 2000, voltou em pauta a internacionalização na estratégia de expansão do BB, impulsionado pela necessidade de fortalecer e manter a liderança do mercado bancário e o apoio estatal como um traço da diplomacia e estratégia de inserção internacional da economia brasileira. A visão do Banco como uma instituição que visa lucro e resultados ficou evidente em dezembro de 2009, quando conseguiu autorização para negociar as suas ações na bolsa de Nova York (VEJA, 2009), em parte utilizado para levantar recursos a fim de impulsionar a sua expansão e aquisição de instituições no exterior. A influência do Estado brasileiro é grande ao cobrar que o Banco se internacionalize dentro do contexto de uma necessidade maior do Brasil. Tanto que o ex-presidente Luiz Inácio Lula da Silva afirmou, em um discurso em 2009, que "o BB precisa virar o banco mais importante da geografia política do nosso continente" (GLOBO, 2009).

O resultado desta nova fase pode ser visto com a compra do Banco da Patagônia, na Argentina, pela quantia de US\$ 480 milhões. O BB passou a deter $51 \%$ do capital votante, totalizando US\$ 479,66 milhões. O Patagônia possuía, em 2009, 2,57 bilhões de dólares em ativos, carteira com mais de 775 mil clientes e 2.660 funcionários (EXAME, 2010). A este fato seguiuse a oficialização do acordo com o banco português Espírito Santo e Bradesco para a expansão das operações na África e, em 2011, a compra, pelo BB do EuroBank na Flórida, EUA. Neste caso, trata-se de pequeno banco com três agências, pelo valor de US\$ 6 milhões².

2 BANCO do Brasil compra banco de pequeno porte nos EUA. Disponível em: < http://www.estadao.com.br/estadaodehoje/20110426/not_imp710741,0.php>. Acesso em: 11/7/2011. 


\section{CONSIDERAÇÕES FINAIS}

O BB, apesar de estatal, reestruturou-se na década de 1990 visando sanear as finanças e voltar a ter solidez. De um lado, as funções públicas são eclipsadas pela necessidade de resultados e de estratégias que permitam satisfazer os investidores privados e transformar a instituição em autossustentável. De outro, as funções públicas ainda estão adicionadas a visão de negócio do BB, mas são utilizadas como vantagens competitivas, e foi criada uma estrutura institucional que não permita que contamine a saúde da instituição.

Sua trajetória no mercado internacional foi beneficiada por tratar-se de um banco público, por um lado e, por outro, reflete as contradições e problemas provocados por esta situação. A trajetória iniciada nas décadas de 1960-70 é bem o reflexo disso. Primeiro houve um intenso crescimento, beneficiado pela abertura de escritórios de representação e agências numa série de cidades nos quatro cantos do mundo. Em seguida, houve uma reviravolta nesta política de internacionalização via implantação de filiais, para focar novamente o banco no mercado nacional, reduzindo tanto o número de agências como de funcionários, mantendo, no entanto, atividades que permitissem as funções estatais de banco público.

$\mathrm{Na}$ nova conjuntura iniciada em meados da década de 1990, o BB deixou para trás a postura de expansão através de abertura de escritórios e agências para comportar-se como uma instituição privada seguindo a necessidade de explorar novos mercados e se firmar como um player internacional. Além do mais, o BB lidera o movimento de internacionalização dos grandes bancos brasileiros, construindo um caminho seguido por Itaú/Unibanco e Bradesco, fazendo o uso de aquisições e parcerias para alavancar a expansão. $\mathrm{O}$ foco da internacionalização recai sobre as Américas, Europa e África, contemplando não apenas o aspecto financeiro e de investimento, mas principalmente o deslocamento das atividades bancárias ao instalar redes de agências e explorar o mercado de varejo.

\section{REFERÊNCIAS}

ARAÚJO, E. L. A. Os bancos públicos frente ao processo de privatização e internacionalização bancária no Brasil nos anos 90. Dissertação (Mestrado em Economia) - Instituto de Economia, Universidade de Campinas, Campinas, 2001.

BANCO DO BRASIL. Relatório anual 2008. Disponível em: <http://www45.bb.com.br/ docs/ri/ra2008/default.htm>. Acesso em: 15/3/2010.

BANCO DO BRASIL. Annual report 2009, 2010.

BANCO DO BRASIL. Banco do Brasil 200 anos de história: 1964-2008. Belo Horizonte: Del Rey, Fazenda Comunicação \& Marketing, 2010.

BANCO DO BRASIL. História do Banco do Brasil. Disponível em: < http://www.bb.com. 
$\mathrm{br} /$ portalbb/page3,102,3527,0,0,1,6.bb?codigoMenu=1193\&codigoNoticia=691\&codigoRet $=3095 \&$ bread $=3>$. Acesso em: 20/2/2011.

BB compra banco argentino Patagônia por US $\$ 480$ milhões. Exame. Disponível em: $<$ http:/ / portalexame.abril.com.br/negocios/noticias/banco-brasil-compra-argentino-banco-patagonia-r-480-milhoes-551747.html>. Acesso em: 25/4/2010.

CARVALHO, C. E.; STUDART, R.; ALVES Jr.; A. J. Desnacionalização do setor bancário e financiamento das empresas: a experiência brasileira recente. Textos para discussão IPEA, n. 882, 2002.

DALLA COSTA, A. ; SOUZA-SANTOS, E. R. A internacionalização dos bancos brasileiros: os casos de Itaú/Unibanco e Banco do Brasil. Economia \& Tecnologia, v. 23, p. 169-179, out./dez. 2010.

LULA cobra internacionalização do BB e sugere novas aquisições de bancos. O Globo, Rio de Janeiro, 21 jul. 2009.

SEEB.Internacionalizaçãodosbancos brasileiros. Disponívelem: <http://www.seebfloripa.com. br $/$ index.php?option $=$ com_content $\&$ view $=$ article\&id $=687$ : bancos-brasileiros\&catid $=79$ :economia $>$. Acesso em: 4/4/2010.

STUDART, R. Investment finance in economic development. Londres: Routledge, 1995. 
